\title{
AS FASES DO PENSAMENTO FENOMENOLÓGICO DE LUDWIG BINSWANGER
}

\author{
Juliana Pita ${ }^{1}$ \\ Virgínia Moreira \\ Universidade de Fortaleza, Fortaleza-CE, Brasil
}

\begin{abstract}
RESUMO. Este artigo tem como objetivo apresentar as três fases do pensamento fenomenológico de Ludwig Binswanger, tal como demarcadas pelo psiquiatra francês Arthur Tatossian. Descreve a construção de sua psicopatologia fenomenológica ao longo destas fases sob a inspiração das filosofias de Husserl e Heidegger, tendo como objetivo a compreensão das experiências psicopatológicas. O psicótico, por exemplo, deve ser compreendido na manifestação de sua experiência vivida. Neste sentido, a oposição entre fatores internos e externos como origem das psicopatologias perde o sentido, pois a importância de enfatizar as características singulares do paciente é destacada ao ser proposta uma compreensão dinâmica deste homem. Entendemos ser importante apontar as fases da psicopatologia fenomenológica de Binswanger por não se tratar de um pensamento fenomenológico linear, mas da evolução de uma psicopatologia inspirada na fenomenologia que nos direciona a um novo espaço na clínica e na psicopatologia, ao possibilitar uma nova forma de compreender a existência humana patológica.
\end{abstract}

Palavras-chave: Ludwig Binswanger; psicopatologia; fenomenologia.

\section{PHASES OF PHENOMENOLOGICAL THOUGHT OF LUDWIG BINSWANGER}

\begin{abstract}
This article aims to present the three phases of phenomenological thought of Ludwig Binswanger as demarcated by the french psychiatrist Arthur Tatossian. It describes the construction of a phenomenological psychopathology along these stages inspired by the philosophies of Husserl and Heidegger with the objective of understanding the psychopathological experiences. The psychotic, for example, should be understood in the manifestation of his lived experience. From this idea, the opposition between internal and external factors as the source of psychopathology is meaningless, since the importance of emphasizing the unique characteristics of the patient is highlighted to propose a dynamic understanding of this man. phenomenological psychopathology Binswanger, because it is not a linear phenomenological thought but an evolution of psychopathology inspired by phenomenology that directs us to a new clinical space and in the psychopathology by enabling a new way of understanding pathological human existence.
\end{abstract}

Key words: Ludwig Binswanger, psychopathology, phenomenology.

\section{FASES DEL PENSAMIENTO FENOMENOLÓGICO DE LUDWIG BINSWANGER}

RESUMEN. Este artículo tiene como objetivo presentar las tres fases del pensamiento fenomenológico de Ludwig Binswanger demarcadas por el psiquiatra francés Arthur Tatossian. Describe la construcción de una psicopatología fenomenológica a lo largo de estas etapas inspiradas en la filosofía de Husserl y Heidegger con el objetivo de comprender las experiencias psicopatológicas. El psicótico, por ejemplo, debe ser entendido en la manifestación de su experiencia vivida. A partir de esta idea, la oposición entre los factores internos y externos como la fuente de la psicopatología no tiene sentido porque la importancia de enfatizar las características únicas del paciente es destacada en la propuesta de una comprensión dinámica de este hombre. Creemos que es importante señalar las fases de la psicopatología fenomenológica de Binswanger porque no es un pensamiento fenomenológico lineal, pero la evolución de la psicopatología inspirada en la fenomenología nos lleva a un nuevo espacio en la clínica y psicopatología, permitiendo una nueva forma de entender la existencia humana patológica.

Palabras-clave: Ludwig Binswanger; psicopatología; fenomenología.

1 Endereço para correspondência: Rua Francisco da Cunha, 1340/1001, Boa Viagem - CEP 51.020-041, Recife/PE, Brasil.E-mail: leodesousafortes@hotmail.com 
A obra de Ludwig Binswanger é fonte de inspiração para a tradição da psicopatologia fenomenológica, sendo pioneira na introdução de um novo olhar e de uma nova forma de compreender a psicopatologia. Isto é tão marcante que Binswanger é considerado por muitos o "pai da psicopatologia fenomenológica" (Van den Berg, 1966; Holanda, 2011; Moreira, 2012).

Binswanger era descendente de uma família tradicional de psiquiatras suíços. Nasceu em 13 de abril de 1881, em Kreuzlingen, na Suíça, e faleceu em 5 de fevereiro de 1966, aos 84 anos. Estudou medicina e filosofia em Lausanne. Em 1907, conheceu Freud pessoalmente, e após esta visita, iniciou uma formação psicanalítica (Fédida, 1970; Kuhn, 2002; Gros, 2009; Cabestan, 2011; Cabestan \& Dastur, 2011; Chamond, 2011; Holanda, 2011; Huygens, 2011). No início da sua carreira de psiquiatra, a psicanálise foi sua base teórica. Cabestan (2011) e Cabestan e Dastur (2011) assinalam que, após este primeiro contato pessoal com Freud, Binswanger iniciou sua prática clínica psicanalítica acreditando que a maioria de seus pacientes deveriam ser objeto de análise.

Cabestan e Dastur (2011) apontam o afastamento de Binswanger da psicanálise após ter contato com as obras de Husserl, antes de 1920, e com a ontologia de Heidegger, após 1927, quando desenvolveu seu pensamento fenomenológico. Embora em alguns momentos tenha estado teoricamente distante da psicanálise, ele não deixou de ter contato com Freud e sua família (Fédida, 1970; Pereira, 2001; Lehfeld, 2011).

Binswanger se opunha à concepção de Freud sobre o homem, o Homo Natura (Cabestan \& Dastur, 2011; Chamond, 2011; Holanda, 2011), por entender a psicanálise como um materialismo. Afirma o filósofo:

Eu penso nesse invisível que une o homo natura de Freud ao fundo original de toda a vida e o distingue de todas as outras ideias naturais do homem e lhe confere sua marca própria, a saber, as pulsões. "O pressentimento sempre nos interessou, ele [Freud] escreve aos 66 anos, que atrás dessas inúmeras pequenas pulsões herdadas se esconde algo sério e poderoso de que nós gostaríamos de nos aproximar com prudência" (Binswanger, 1936/1970, p. 202).

Binswanger (1924/1971) recusava a cisão entre o elemento psíquico e o corporal, pois considerava o ser humano como uma existência em sua história de vida. O psicótico, por exemplo, deve ser compreendido na manifestação de sua experiência vivida. Partindo desta ideia, a oposição entre fatores internos e externos como origem das psicopatologias perde o sentido, pois a importância de enfatizar as características singulares do paciente é ressaltada ao ser proposta uma compreensão dinâmica e viva deste homem. Reconhecemos aí um presságio da inserção da antropologia no campo psicopatológico.

Afirma Binswanger (1924/1971):

Em tal "alteração cerebral", nós devemos ver uma alteração funcional do organismo - que, nós sabemos hoje, abrange bem mais que o córtex e o cérebro inteiro -, e pode representar uma alteração, uma desordem, um transtorno ou uma modificação de humor bastante profunda da pessoa, no sentido de Kraus, à qual é necessário, naturalmente, acrescentar o transtorno das funções psíquicas do organismo. A emoção, o momento psicogênico, sobretudo, engloba e atrapalha aparentemente de maneira direta o curso da função psíquica e física, enquanto que isso não parece ser o caso na histeria, onde o transtorno do curso da função parece depender das reações psíquicas de natureza "bem definida" pelo conteúdo de experiências exteriores vividas (pp. 51/52).

Livre desta homogeneização entre os conceitos de função psíquica e de conteúdo espiritual das experiências vividas, o homem é reconhecido como "um organismo que funciona de tal maneira e que vive em uma história" (Binswanger, 1924/1971, p. 53). Assim, para ele, não existe história de vida sem um organismo, muito menos um organismo sem sua história.

Este distanciamento teórico da psicanálise encaminhou Binswanger para uma abordagem da consciência. Sua psicopatologia fenomenológica não buscava uma verdade do sintoma ocultada pelo inconsciente, como era entendida pela Psicanálise. $\mathrm{Na}$ perspectiva fenomenológica de Binswanger, o paciente é o intérprete de seu próprio sofrimento, desaparecendo, então, a ideia de inconsciente psicanalítico (Chamond, 2011).

O contato com a fenomenologia descritiva de Husserl fortalece a ideia de Binswanger sobre a inexistência de um inconsciente no sentido freudiano. Ao destacar a noção de inconsciente, 
Freud separava o homem de suas relações com o mundo, provocando sua despersonalização ao apresentá-lo como um aparelho psíquico (Cabestan, 2011; Cabestan \& Dastur, 2011; Holanda, 2011; Lehfeld, 2011). Na perspectiva fenomenológica, o vivido de cada homem faz parte de uma estrutura complexa, estando o inconsciente sempre presente nesta existência humana. Segundo Leroy-Viémon (2011) e Cabestan e Dastur (2011), Binswanger compreende o homem em sua existência e o inconsciente como um modo desta existência no mundo, e não em oposição à consciência.

Cabestan e Dastur (2011) identificam a "impossibilidade de diálogo" (p. 176) teórico entre Binswanger e Freud, e foi a descrição fenomenológica de Husserl o que permitiu a distinção entre as questões psicanalíticas e as psicopatológicas. A fenomenologia husserliana se torna uma das inspirações do pensamento fenomenológico de Binswanger por facilitar a desconstrução do psicologismo, sendo, assim, identificada como a passagem de uma compreensão naturalística para uma compreensão antropológica da psicose. Esta nova forma de olhar as psicopatologias, proposta por Binswanger, possibilita a abertura de um novo espaço dentro do campo da psiquiatria, ao oferecer uma maneira diferente de interrogar sobre a existência humana: um olhar fenomenológico.

Cabestan e Dastur (2011) afirmam:

\begin{abstract}
Sem dúvida Freud e Binswanger permaneceram até o fim ligados por um certo sentido compartilhado pela sua amizade; mas quando ele descobre a possibilidade de uma Daseinsanálise médica, Binswanger se volta irremediavelmente a um pensamento que exerceu nesses anos de formação uma influência tão decisiva quanto incontestável, mas que, vinda a maturidade, não tem mais nada de fundamental a lhe oferecer (p. 177).
\end{abstract}

O trabalho de Binswanger questiona os princípios fundamentais da psiquiatria e esclarece o papel do psiquiatra na compreensão das psicopatologias. Conforme Gros (2009), esta proposta era localizar os fundamentos teóricos que serviriam de amparo à sua prática clínica. Para isto, sua formação intelectual parte de duas fontes: a psiquiatria e a filosofia (Chamond, 2011; Holanda, 2011). Podemos dizer que esta inspiração filosófica permite a Binswanger criticar o pensamento objetivante das ciências da natureza, por estas se limitarem a uma compreensão orgânica do homem. O filósofo estabelece comunicação entre fenomenologia e psiquiatria ao formular uma antropologia fenomenológica como fonte de inspiração para a psiquiatria.

Ao longo de sua trajetória, a psicopatologia fenomenológica de Binswanger se apoia, principalmente, nas fenomenologias de Edmund Husserl e Martin Heidegger. Diante disso, Tatossian (1979/2006) divide este pensamento em fases. Este artigo tem como objetivos: 1)apresentar as três fases fenomenológicas do pensamento de Binswanger a partir da demarcação proposta por Tatossian (1979/2006); e 2)- descrever a construção da psicopatologia fenomenológica ao longo destas fases.

\section{PRIMEIRA FASE: A ANTROPOLOGIA FENOMENOLÓGICA NA PSICOPATOLOGIA}

A fenomenologia de Husserl foi introduzida no campo da psicopatologia em dois textos de Binswanger, ambos de 1922: L'Introduction aux problèmes de psychologie générale e De la Phénoménologie. O aprofundamento fenomenológico adquirido nas obras de Husserl ofereceu elementos para que Binswanger pudesse se desprender da psicanálise freudiana e das ciências naturalistas, as quais ele questionava. Para Gros (2009), a fenomenologia husserliana possibilitou a Binswanger reconhecer a distinção entre 0 método fenomenológico e o pensamento objetivante dos naturalistas.

Para Binswanger (1971a), a pretensão da fenomenologia de Husserl era ser a ciência dos fenômenos da consciência e das essências, e isto serviria como ferramenta de compreensão dos fenômenos psicóticos.

Assim, 
chamamos o método fenomenológico, isto é, caminhar passo a passo no percurso que conduz do fato particular individual e empírico até a essência pura, que é geral e ultrapassa o empírico. É apenas aqui que começa o interesse da psiquiatria pela fenomenologia (Binswanger, 1971a, p. 87).

Em ambos os textos de 1922, L'Introduction aux problèmes de psychologie générale e De la Phénoménologie, o conceito husserliano de intencionalidade está presente, pois permite a Binswanger mergulhar na constituição da consciência, possibilitando o alcance das alterações psicopatológicas originadas da falha na constituição da experiência temporal. Segundo Gros (2009), o conceito de intencionalidade permite a ultrapassagem da cisão sujeito/objeto, facilitando, assim, a inserção de Binswanger em discussões no campo psicológico.

A psicopatologia de Binswanger, inspirada na fenomenologia, inicialmente chamada antropologia fenomenológica, tinha como objetivo inserir a psicopatologia em um campo distinto das ciências naturais e do trabalho proposto por Jaspers em Psicopatologia Geral, de 1913. Ele desejava que a antropologia fenomenológica se tornasse o fundamento da psicopatologia e da psiquiatria, por compreender o homem a partir de sua existência na história (Cabestan \& Dastur, 2011; Kuhn e Maldiney, 1971; Lehfeld, 2011; Moreira, 2012).

O esboço da psicopatologia fenomenológica proposto por Binswanger não é reconhecido como uma novidade (Cabestan \& Dastur, 2011), já que o termo fenomenologia havia sido introduzido no campo da psicopatologia antes de 1922, em um artigo de 1912 do psiquiatra alemão Karl Jaspers no qual a fenomenologia era mostrada como método de descrição dos vividos conscientes das doenças mentais. Podemos dizer que Jaspers inaugurou a psicopatologia como um campo específico de saber que contava com a compreensão subjetiva adquirida com a fenomenologia descritiva husserliana (Holanda, 2011; Moreira, 2012), mas foi Binswanger quem iniciou a psicopatologia fenomenológica propriamente dita.

Afirmam Cabestan e Dastur (2011):

De um ponto de vista metodológico, a fenomenologia está longe de ocupar um lugar privilegiado no tratado de 1913: ela é somente um método entre outros cuja ferramenta é a compreensão e, notadamente, a capacidade do observador de se colocar no lugar do outro por empatia (Einfühlung). Mas essa compreensão estática (fenomenológica no sentido de Jaspers) das vivências é somente uma prévia de uma compreensão genética que visa a entender $\mathrm{o}$ encadeamento dos estados psíquicos (o homem atacado fica com raiva, o que foi enganado se torna desconfiado) e a liberar a partir dos fatos empíricos das relações típicas fundamentais. Nessa mesma perspectiva, a Psicopatologia geral se vincula igualmente a fixar tipos de patologia como tipos de demências ou tipos de personalidades, tais como o tipo histérico ou o tipo psicastênico (pp. 53-54).

Apropriando-se do método fenomenológico, Binswanger (1971a) apresentou uma nova forma de olhar a psicopatologia, a qual passou a ser compreendida a partir da experiência vivida do psicótico, já que o método fenomenológico ofereceria respostas aos seus questionamentos psicopatológicos (Moreira e Pita, 2012).

Mesmo reconhecendo a diferença entre o método fenomenológico e a pesquisa psicopatológica, Binswanger (1971a) faz referência a uma fenomenologia psicopatológica. Distanciando-se destas divergências, ele se direciona a uma fenomenologia que não se limita a descrever o quadro psicopatológico, e define como a principal tarefa da fenomenologia oferecer ao psicopatologista uma nova possibilidade de compreender 0 homem psicótico. Desta forma ele dava um novo direcionamento à essência da coisa mesma. Não se trataria mais de compreender o psicótico a partir de um pensamento naturalista ou psicológico, mas de buscar uma apreensão do mundo do psicótico como ele o experiencia.

Neste sentido, Binswanger (1971a) afirma:

O fundamento da psicologia reside, sobretudo, na percepção do outro, na percepção de um eu estranho ou de outrem, bem mais raro que do próprio eu. O objeto de pesquisa, aqui, não é mais a apreciação no sentido introspectivo ou na auto-observação, mas nesse modo de percepção através do qual nós percebemos o caráter próprio da vida psíquica de outrem ( $p$. 101). 
Nesta primeira fase do pensamento fenomenológico de Binswanger a contribuição do olhar fenomenológico para a psicopatologia é oferecida através da descrição dos vividos do psicótico, ou seja, dos fenômenos tal como aparecem em sua consciência; assim, o "ego transcendental esquizofrênico" (Binswanger, 1971a, p. 108) não deve mais ser compreendido como objeto de ciência, mas como essência.

Para Binswanger (1971a), compreender fenomenologicamente o mundo psicótico não significa olhar um mundo comum, pois este mundo é formado de maneira diferenciada, pelo contato com o outro; um mundo que é complicado apreender apenas com uma descrição de seu paciente. Só seria possível entender este mundo psicótico distanciando-se dos conhecimentos prévios da psicopatologia. Com esta abordagem fenomenológica, o fenômeno psicopatológico jamais seria visto isoladamente e sua essência estaria sempre relacionada à manifestação de cada paciente, portanto o paciente seria conhecido a partir de um determinado fenômeno e, inversamente, este fenômeno penetraria este paciente.

Gros (2009) levantou um questionamento ao aproximar os trabalhos de Binswanger, em sua primeira fase fenomenológica, mais de uma questão metodológica do que de uma psicopatologia de cunho fenomenológico. O pensamento fenomenológico de Husserl não responde a todos os questionamentos de Binswanger em relação à psicopatologia; e o principal papel da fenomenologia husserliana, nesta primeira fase fenomenológica, era facilitar a elaboração de uma base para uma fase seguinte. Com isto, Tatossian (1979/2006) justifica a passagem para uma segunda fase do pensamento fenomenológico de Binswanger, tendo em vista o desejo de ampliar o conceito de intencionalidade de Husserl ao se fundamentar em Ser e Tempo de Heidegger.

\section{SEGUNDA FASE: BINSWANGER APÓS A LEITURA DE SER E TEMPO}

A analítica existencial heideggeriana em Ser e Tempo apresenta as estruturas ontológicas da existência humana, as quais estão presentes na vida de cada homem (Chamond, 2011). Nesta segunda fase de seu pensamento fenomenológico, o conceito de Dasein fornece a Binswanger a oportunidade de aprofundar a descrição do paciente psicótico a partir de sua existência no mundo. A introdução deste conceito provoca uma modificação na antropologia fenomenológica de Binswanger que se torna Daseinsanálise (Tatossian, 1979/2006).

Le Rêve et l'existence é a primeira publicação de Binswanger após a leitura de Ser e Tempo. Neste texto sobre os sonhos delineiam-se os aspectos iniciais da Daseinsanálise e, pela primeira vez, explicam-se antropologicamente os movimentos existenciais de queda e ascensão, que são mostrados como duas direções existenciais correspondentes às estruturas do mundo:

É dessa maneira igualmente que o
enfraquecimento ou a queda representa
uma direção significativa geral do alto
em direção ao baixo; ela toma, através
de nosso Dasein uma significação
existencial particular segundo o
"existencial ontológico", ou seja, a
espacialidade em sua extensão sempre
mais distante, o abandono da
receptividade ou a explicação do ato de
compreensão (Binswanger, 1971b, p.
201).

A psicopatologia fenomenológica não compreende $\mathrm{o}$ homem doente como um organismo psicofísico, sendo o conceito de Dasein necessário para Binswanger, por permitir o alcance das formas psicóticas, as quais não haviam sido atingidas através da fenomenologia descritiva de Husserl. Com esta contribuição, a experiência psicótica deixa de ser objeto para ser o sujeito da psiquiatria.

Binswanger elabora a Daseinsanálise como tentativa de ampliar e refinar a psicanálise com conceitos heideggerianos, além de mesclá-la com conhecimentos oferecidos pela filosofia e pela antropologia. Primeiramente a Daseinsanálise, é desenvolvida como um método e em seguida torna-se uma forma de intervenção terapêutica destinada a compreender o mundo vivido dos pacientes psicóticos, ou seja, a descrição do mundo a partir do homem como uma existência neste mundo (Moreira \& Pita, 2012).

Segundo Cabestan e Dastur (2011),

É o que explica que a Daseinsanálise
biswangeriana se caracteriza pela
oposição à psicanálise, que nasceu de
uma motivação propriamente
terapêutica, por uma preocupação,
sobretudo científica, oriunda da
insatisfação de ver que falta à


psicopatologia um verdadeiro fundamento epistemológico. É, portanto, com uma intenção de abordagem metodológica que Binswanger se lançou à dominação do método das ciências naturais no campo da psiquiatria (p. 57).

Conforme refere Chamond (2011), Binswanger define Daseinanálise como uma ciência empírica da compreensão antropológica do homem oposta às formas de compreensão humana das ciências naturalistas. Para esta autora, Binswanger compreende a existência subjetiva do homem em sua totalidade, como ser presente neste mundo; assim, Daseinsanálise significa uma análise da existência humana.

Para Binswanger (1932/1998; 1971b), o homem não pode se realizar em sua existência quando há desproporções entre as dimensões espaciais de seu Dasein. Estas desproporções surgem por meio de um maior direcionamento de sentido e uma "flexão excessiva da existência comum" (Chamond, 2011, p. 06), funcionando como um bloqueio da existência humana. Assim, a Daseinsanálise tem como finalidade compreender e descrever a experiência humana, tentando alcançar a experiência humana inautêntica ou alterada do psicótico e procurando conhecimentos sobre os modos como este Dasein alterado se manifesta em seus pacientes (Teixeira, 1997; Moreira, 2012).

Conquanto o Dasein fosse o conceito fundamental desta proposta daseinsanalítica, o pensamento fenomenológico de Binswanger permaneceu mais conectado ao de Husserl (Tatossian, 1979/2006; Moreira, 2010). Este fato foi reconhecido por Heidegger em seus seminários em Zollikon, de 1965, ao demarcar que "a fenomenologia de Husserl, que ainda o influencia [Binswanger], a qual permanece fenomenologia da consciência, impede a visão clara da hermenêutica fenomenológica do Dasein" (Heidegger, 1987/2006, p. 146).

A insatisfação de Binswanger persiste por ainda não ter encontrado bases suficientes para compreender a constituição do mundo psicótico. Nisto Tatossian (1979/2006) identifica o início de uma terceira fase fenomenológica no pensamento de Binswanger, quando este retorna à fenomenologia husserliana. Neste período, Binswanger se depara com uma fenomenologia da subjetividade, do Ego transcendental em Husserl, não mais aquele da fenomenologia descritiva, que marcou sua primeira fase fenomenológica.

\section{TERCEIRA FASE: A REVIRAVOLTA FENOMENOLÓGICA DO ÚLTIMO BINSWANGER}

Neste terceiro momento fenomenológico Binswanger se inspira nas interpretações dos textos de Husserl realizadas pelo amigo e fenomenólogo húngaro Wilhelm Szilasi, cuja principal obra é Introduction à la Phénoménologie d'Edmond Husserl, de 1959.

A reviravolta fenomenológica do último Binswanger não faz referência a uma fenomenologia descritiva nem antropológica, pois esta é uma fenomenologia genética e constitutiva centrada na subjetividade. Assim,

\begin{abstract}
Aqui a intenção de Binswanger não é mais de descrever o mundo maníaco constituído como ele o faria nas Ideenflucht (Fuga de Ideias), ou o mundo melancólico como o faria a fenomenologia antropológica do tempo vivido, mas tratar o problema da constituição desses mundos como do Ego que aparece aí ou de Outrem que aí é encontrado (Tatossian, 1979/2006, p. 157).
\end{abstract}

Nos dois últimos livros escritos por Binswanger, Mélancolie et manie e Délire, é evidente a busca pela constituição da experiência psicótica a partir da utilização de conceitos husserlianos. Assim, Cabestan e Dastur (2011) identificam que o interesse não se encontra mais na descrição destes mundos psicóticos. A reaproximação de Binswanger com os conceitos husserlianos não significa o total abandono das contribuições daseinsanalíticas, mas a busca por uma nova constituição transcendental e intencional a partir das bases da ontologia do Dasein. Por isso em sua última fase é identificada a compreensão das falhas estruturais do Dasein na psicose.

Inspirado na noção de fluxo temporal, a partir da obra husserliana Sur la phénoménologie de la conscience intime du temps, Binswanger (1960/1987) aponta a retenção, apresentação e protensão como correspondentes das objetividades temporais passado, presente e futuro. Estes correspondentes intencionais devem funcionar fluidamente, e não de maneira desconexa, como aparece nas psicoses.

Em Mélancolie et manie, Binswanger mostra estas duas formas psicóticas de funcionar no mundo como falhas nesta constituição da temporalidade humana. Ao demonstrar a constante vinculação entre os elementos 
temporais, Binswanger (1960/1987) esclarece que, a partir disto, por exemplo, é mais fácil identificar que o melancólico não se desvincula de seu passado, tendo sua existência dominada pelos acontecimentos anteriores enquanto 0 presente perde seu significado por estar completamente vazio.

Em sua última fase, a análise psicopatológica feita por Binswanger (1960/1987) é retomada com os estudos sobre a mania, de forma diversa da antropologia do mundo maníaco apresentada anteriormente em seu livro Sur la fuite des idées. A mania é entendida como uma falha da apresentação temporal em que o relaxamento temporal no maníaco ocorre de forma inversa em relação à melancolia, pois se caracteriza pelo desaparecimento de toda retenção e protensão. Para o último Binswanger, a diferença entre a melancolia e a mania é que o melancólico se encontra preso em seu passado e o maníaco, no presente; logo, o maníaco experiencia um constante agora e o melancólico não consegue viver seu presente por estar preso a um acontecimento anterior.

Como as análises das psicoses feitas pelo último Binswanger foram realizadas a partir de sua inspiração na análise fenomenológica husserliana da temporalidade, para Cabestan e Dastur (2011), ele percorre este caminho em constante comunicação com a fenomenologia transcendental de Husserl, já que as psicoses são identificadas como transtornos da constituição da subjetividade e de sua temporalidade.

Para Cabestan e Dastur (2011), tratava-se de

compreender a constituição particular dos mundos psicóticos, esquizofrênicos, melancólicos e maníacos, interrogando os momentos estruturantes desses universos a partir da "correlação" que eles pressupõem entre a Leistung, a produção transcendental do sujeito e a objetividade assim constituída, o produto transcendental intramundano que se dá deste modo (p. 76).

O último Binswanger, fortemente marcado pela fenomenologia egológica husserliana, transforma-se teoricamente. Ele abandona, embora não por completo, a compreensão do Dasein, e segue em direção ao sujeito transcendental do Ego puro. Este movimento ocorre, segundo Cabestan e Dastur (2011), devido à sua dificuldade em compreender as psicoses apenas através da Daseinsanálise.
Embora alguns autores - entre eles Tatossian (1979/2006) - tenham sugerido um distanciamento da Daseinsanálise, Binswanger (1965/2010) se defende ao dizer que a introdução da fenomenologia genética jamais o afastaria da Daseinsanálise. Diante disto, a introdução da fenomenologia genética pode significar a possibilidade de uma compreensão mais aprofundada da ontologia heideggeriana (Cabestan e Dastur, 2011).

Cabestan e Dastur (2011) afirmam:

Pois esse método não é fenomenológico apenas no sentido da psicologia "descritiva" brentaniana, cujo primeiro Husserl ainda se apoiava, mas no sentido forte de ciência transcendental com relação à estrutura a priori da experiência, no sentido, então, no qual a doutrina husserliana da consciência intencional constitui, como o declara Binswanger, "a única ciência que nos permite realizar aquilo que as doutrinas do organismo ou a biologia realizam para a medicina do corpo" (p. 76).

Esta passagem da Daseinsanálise à fenomenologia genética transcendental é entendida por Tatossian (1979/2006) como uma mudança de uma atitude impregnada da historicidade oferecida pela Daseinsanálise para uma perspectiva a-histórica através da fenomenologia genética. Por isso Binswanger é fortemente criticado ao abandonar a história de vida do paciente e limitar-se à doença.

Entendemos que, por mais que tenha sido criticado por Tatossian (1979/2006) por abandonar uma perspectiva heideggeriana com foco na história de vida do paciente e retroceder a uma compreensão das doenças, o último Binswanger representa o período mais criativo da obra deste psiquiatra suíço. Por isto não vemos sua última fase fenomenológica como um recuo, mas como um momento em que ele está mais amadurecido, com um olhar fenomenológico mais fértil e profundo, para compreender os psicóticos acompanhados em seus atendimentos psiquiátricos.

\section{CONCLUSÃO: A CONSTRUÇÃO DA PSICOPATOLOGIA FENOMENOLÓGICA}

\begin{tabular}{lllr} 
A & \multicolumn{2}{c}{ psicopatologia } & fenomenológica \\
desenvolvida & por & Ludwig & Binswanger foi \\
responsável & por & inserir & os estudos
\end{tabular}


psicopatológicos em um contexto diferenciado da psicopatologia tradicional. Inspirada na fenomenologia, essa psicopatologia introduz um novo olhar para compreender os pacientes psicóticos, ao enfatizar a importância da história de vida do paciente e de sua experiência vivida.

Apresentar a construção da psicopatologia fenomenológica de Binswanger, através das fases demarcadas pelo psiquiatra francês Arthur Tatossian nos permite mostrar que a inspiração fenomenológica sofrida por Binswanger ao longo de seu pensamento fenomenológico não estava atrelada exclusivamente aos conceitos heideggerianos, como é mais comumente conhecida em nosso meio, mas estava inspirada, principalmente, na fenomenologia de Husserl. Este fato se evidencia na terceira fase de seu pensamento, a qual representa a finalização de sua proposta de psicopatologia fenomenológica e demarca o período mais criativo do retorno de Binswager à fenomenologia husserliana.

Concluímos que a construção da psicopatologia fenomenológica desenvolvida por Ludwig Binswanger, descrita neste artigo através de suas fases, leva-nos a uma compreensão da psicopatologia influenciada principalmente por dois grandes nomes da fenomenologia filosófica: Husserl e Heidegger. Compreender estas fases nos permite explicitar que não se trata de um pensamento fenomenológico linear, mas da evolução de uma psicopatologia inspirada na fenomenologia que nos direciona a um novo espaço na clínica, possibilitando a busca por compreender a existência psicopatológica humana a partir da experiência vivida.

\section{REFERÊNCIAS}

Binswanger, L. (1970). La conception freudienne de l'homme à la lumière de l'anthropologie. In L. Binswanger, Analyse existentielle et psychanalyse freudienne (pp. 201-237). Paris: Gallimard (Original publicado em 1936).

Binswanger, L. (1971). Fonction Vitale et histoire intérieure de la vie. In L. Binswanger, Introduction à l'analyse existentielle (pp. 49-77). Paris: Les Éditions de Minuit (Original publicado em 1924).

Binswanger, L. (1971a). De la Phénoménologie. In L. Binswanger, Introduction à l'analyse existentielle (pp. 79117). Paris: Les Éditions de Minuit (Original publicado em 1922).

Binswanger, L. (1971b). Le rêve et l'existence. In L. Binswanger, Introduction à l'analyse existentielle (pp. 199-225). Paris: Les Éditions de Minuit (Original publicado em 1930).
Binswanger, L. (1987). Mélancolie et manie: études phénoménologiques. Paris: Presses Universitaires de France (Original publicado em 1960).

Binswanger, L. (1998). Le problème de l'espace en psychopathologie. Toulouse: Presses Universitaires du Mirail (Original publicado em 1932).

Binswanger, L. (2010). Délire. Grenoble: Jérôme Millon (Original publicado em 1965).

Cabestan, P. \& Dastur, F. (2011). Daseinsanalyse. Paris: Librairie philosophique J. Vrin.

Cabestan, P. (2011). Résistance. Binswanger et la psychanalyse freudienne. In B. Leroy-Viémon (Org.), Ludwig Binswanger: philosophie, anthropologie clinique, daseinsanalyse (pp. 165-183). Argenteuil: Le Cercle Herméneutique Editeur.

Chamond, J. (2011). Fenomenologia e psicopatologia do espaço vivido segundo Ludwig Binswanger: uma introdução. Revista da Abordagem Gestáltica, v. XVII, n. 1, 3-7, jan-jun.

Fédida, P. (1970). Préface. In L. Binswanger, Analyse existentielle et psychanalyse freudienne: discours, parcours et Freud (pp. 9-37). Paris: Gallimard.

Gros, C. (2009). Ludwig Binswanger. entre phénoménologie et expérience psychiatrique. Chatou: Les Éditions de La Transparence.

Heidegger, M. (2006). Seminários de Zollikon. Petropólis: Vozes (Original publicado em 1987).

Holanda, A. F. (2011). Gênese e histórico da psicopatologia fenomenológica. In: V. Angerami-Camon (Org.), Psicoterapia e brasilidade. São Paulo: Cortez Editora, 2011, 57-82.

Huygens, A. (2011). De la psychanalyse à l'analyse du Dasein: au-delà d'un passage, un saut. In B. LeroyViémon (Org.), Ludwig Binswanger: philosophie, anthropologie clinique, daseinsanalyse (pp. 269-287). Argenteuil: Le Cercle Herméneutique Editeur.

Kuhn, R. \& Maldiney, H. (1971). Préface. In L. Binswanger, Introduction à l'analyse existentielle (pp. 724). Paris: Les Éditions de Minuit.

Kuhn, R. (2002). L'œuvre de Ludwig Binswanger, son origine et sa signification pour l'avenir. In P. Fédida. \& M. WolfFédida (Org), Phénoménologie, Psychiatrie, Psychanalyse (pp. 35-45). Paris: Colletion Phéno.

Lehfeld, B. (2011). Le premier Binswanger. In B. LeroyViémon (Org.), Ludwig Binswanger: philosophie, anthropologie clinique, daseinsanalyse (pp. 37-61). Argenteuil: Le Cercle Herméneutique Editeur.

Leroy-Viémon, B. (2011). Actualité de Binswanger pour la psychothérapie. In B. Leroy-Viémon (Org.), Ludwig Binswanger: philosophie, anthropologie clinique, daseinsanalyse (pp. 7-15). Argenteuil: Le Cercle Herméneutique Editeur.

Moreira, V. \& Pita, J. (2012). A noção de delírio em Ludwig Binswanger e Arthur Tatossian. In A. Tatossian \& V. Moreira (Org.), Clínica do Lebenswelt: psicoterapia e psicopatologia fenomenológica (pp. 263-276). São Paulo: Escuta.

Moreira, V. (2010). Possíveis contribuições de Husserl e Heidegger para a clínica fenomenológica. Psicologia em Estudo, Maringá, 15(4), 723-731. 
Moreira, V. (2012). A contribuição de Jaspers, Binswanger, Boss e Tatossian para a psicopatologia fenomenológica. In A. Tatossian \& V. Moreira (Org.), Clínica do Lebenswelt: psicoterapia e psicopatologia fenomenológica (pp. 189-217). São Paulo: Escuta.

Pereira, M. (2001). Sobre os fundamentos da psicoterapia de base analítico-existencial, segundo Ludwig Binswanger. Revista Latinoamericana de Psicopatologia Fundamental, 4 (1), 137-142.

Tatossian, A. (2006). Fenomenologia das psicoses (J. C. Célio e V. Moreira, Trad.) . São Paulo: Escuta (Original publicado em 1979).

Teixeira, J. A. C. (1997). Introdução às abordagens fenomenológica e existencial em psicopatologia: as abordagens existenciais. Análise Psicológica, 2 (XV), 1997, 195-205.
Van den Berg, J. H. (1966). O paciente psiquiátrico: esboço de psicopatologia fenomenológica. São Paulo: Mestre Jou.

Recebido em 06/06/2013 Aceito em 01/10/2013

Juliana Pita: psicóloga, mestre pelo Programa de Pós-Graduação em Psicologia da Universidade de Fortaleza (UNIFOR).

Virgínia Moreira: doutora em Psicologia Clínica pela Pontifícia Universidade Católica de São Paulo, pós-doutorado em Antropologia Médica pela Harvard University, professora titular do Programa de Pós-Graduação em Psicologia da Universidade de Fortaleza (UNIFOR). 